\title{
Higher division of sciatic nerve and its clinical importance
}

\author{
Shamima Banoo ${ }^{1 *}$, Mohd. Saleem Itoo ${ }^{2}$, Pandith Tafiq John ${ }^{3}$, Parveen Akhter ${ }^{1}$, Fahmida Akhter ${ }^{3}$, \\ Omer Bashir itoo ${ }^{3}$, Javeed Khan ${ }^{1}$, Yasmeen Jan ${ }^{1}$, Sabia Nazir ${ }^{1}$, Zahid Bashir ${ }^{1}$, Gh.Mohd Bhat ${ }^{4}$, \\ Shafaq Masood ${ }^{3}$, Rayees Ahmad Bhat ${ }^{3}$, Kowsar Jan ${ }^{3}$ \\ ${ }^{1}$ Lecturer Department of Anatomy Government Medical College Srinagar/Jammu, J\&K, India \\ ${ }^{2}$ Assistant professor Department of Anatomy Government Medical College Srinagar, J\&K, India \\ ${ }^{3}$ Assistant Surgeon Department of Anatomy/Medicine Government medical College Srinagar J\&K, India \\ ${ }^{4}$ Associate Professor Department of Anatomy Government Medical College Srinagar J\&K, India \\ *Corresponding author E-mail: drshamimagmc@gmail.com
}

Copyright $(\mathcal{C} 2014$ Shamima Banoo et al. This is an open access article distributed under the Creative Commons Attribution License, which permits unrestricted use, distribution, and reproduction in any medium, provided the original work is properly cited.

\begin{abstract}
The Sciatic Nerve after originating from sacral plexus leaves the pelvis through the lower part of greater sciatic foramen into the gluteal region and divides into two components at any level from its origin to its usual division inside the upper part of popliteal fossa. The Present study was conducted in the Department of Anatomy Government Medical College Srinagar to study the variations in the level of division of the sciatic nerve during usual dissection for academic purposes. Both lower limbs of a middle aged formalin preserved Indian male cadaver were dissected out for routine teaching and simultaneously recording observations. It was observed that the left sided sciatic nerve divided into its two components inside the pelvis. The tibial and common peroneal nerves after leaving through greater sciatic foramen sandwiched piriformis muscle in the gluteal region. The common peroneal nerve passed above the piriformis where as the tibial nerve passed inferior to this muscle. The sciatic nerve on the other side of this cadaver followed the normal anatomical course. The higher division of sciatic nerve inside the pelvis though rare is of great academic and clinical significance in Neurology, General Surgery, Orthopaedics, Anaesthesiology, Sports medicine and physiotherapy. The knowledge of this variation is also important for paramedics who frequently give intramuscular injections into the gluteal region.
\end{abstract}

Keywords: Common Peroneal Nerve, Greater Trochanter, Hamstring Muscles, Ischial Spine, Sciatic Nerve.

\section{Introduction}

The Sciatic nerve is the thickest nerve in our body [1]. It is the largest branch of sacral plexus (L4, L5, S1, S2, and S3). It is a composite nerve consisting of two divisions united by connective tissue [2], [3]. It originates from sacral plexus (L4, 5, S1-3) and is the largest [2] and thickest nerve [4] of our body being 2 centimeters thick at its commencement [2], [4]. The two components of sciatic nerve are bound together in the same connective tissue sheath (epineurium). It consists of medially placed tibial nerve to hamstring muscles and laterally placed common peroneal nerve and its branch to short head of biceps. It originates in pelvis and divides into its two terminal branches namely the tibial and the common peroneal (common fibular) nerves at the level of lower and middle thirds of thigh. However the exact level of division into terminal branches varies. There are available reports in the literature where sciatic nerve divides into terminal branches high up inside the pelvis or in the gluteal region or in the upper thigh [1]. The tibial component is medial and consists of ventral divisions of anterior primary rami of L4,L5,S1,S2,S3.The common Peroneal part is formed by the dorsal divisions of the anterior primary rami of L4,L5,S1,S2. Normally the Sciatic Nerve leaves from pelvis and enters into the gluteal region through the greater sciatic foramen below the Piriformis. This nerve innervates the muscles of the posterior compartment of thigh and through its terminal branches it supplies all the muscles of the leg and foot. It is the sole sensory nerve of leg and foot except for an area supplied by saphenous nerve. Occasionally the two nerves are separate, in this case the tibial nerve leaves inferior to piriformis and common peroneal either pierces this muscle or passes superior to it [1]. In 10-12 percent of cases the sciatic nerve divides before entering the gluteal 
region and common peroneal nerve passes through the muscle. In 0.5 percent of cases common peroneal nerve passes superior to the muscle in that case it is vulnerable to injury during intragluteal injections [2]. Knowledge of its course through the gluteal region mid-way between the ischial tuberosity and the greater trochanter of femur is clinically important. Because of the large sciatic nerve the buttock has side of safety (its lateral side) and a side of danger (its medial side). Wounds or surgery on its medial side are liable to injure the sciatic nerve and its branches to the hamstring muscles on the back of thigh. Paralysis to these muscles results in impaired hip extension and knee flexion.

\section{Materials and methods}

This present study was carried out in the Department of Anatomy Government Medical College Srinagar, Kashmir, India by dissecting a middle aged formalin preserved Indian male cadaver for routine teaching purposes and recording observations. Both lower limbs of this cadaver were carefully dissected out strictly following instructions given in the Cunningham's manual of practical Anatomy [5] and observed for variations in the division of sciatic nerve. Appropriate photographs were taken and labeled.

\section{Case report}

We report a case in which the left sciatic nerve divided inside the pelvis into its two terminal branches. The common peroneal nerve passed above and over the piriformis whereas the tibial nerve passed below the piriformis muscle as shown in the fig, [1]. The origin, course and division of the sciatic nerve on the right side of this cadaver was normal.

\section{Discussion}

There are available reports in the literature [1-5] related to the variable division of sciatic nerve but its division inside the pelvis is not so common. The nerve originating from sacral plexus being the largest [2] and thickest [3] nerve of our body leaves through greater sciatic foramen and passes below piriformis muscle and divides into its terminal branches usually at the level of superior angle of popliteal fossa [2-4]. This composite nerve [2] can divide into its two branches at any level higher than this, even inside the pelvis but never below the inferior angle of popleteal fossa [4]. This nerve has two components tibial nerve and common peroneal nerve united by connective tissue. The sciatic nerve supplies the knee flexors and all muscles below the knee [4]. Tibial part of sciatic nerve supplies the ischial (hamstring) part of adductor magnus and hamstrings except the short head of biceps femoris which is supplied by common peroneal nerve [5] .The common peroneal nerve (L4,5,S1-2) supplies the anterior and lateral compartment of leg as well as the major part of the skin over dorsum of the foot [6]. The tibial nerve is the nerve of posterior compartment of leg and the sole of foot. It is derived from the ventral divisions of $\mathrm{L} 4,5, \mathrm{~S} 1,2,3$. The complete traumatic palsy of the sciatic nerve is rare and results in flail foot and severe difficulty in walking. The nerve is also vulnerable to injury in posterior dislocation of hip. Sciatic nerve leaves the pelvis either behind the piriformis or sometimes through this muscle [2], [4] and may become entrapped in it (the piriformis syndrome) [4]. Prolonged external compression on the buttock over a hard surface in bed ridden patients can injure the nerve. Mohd.Saleem Itoo et al (2011) [7] reported a case of higher division of sciatic nerve in a middle aged formalin preserved male cadaver where this nerve followed the usual anatomical course up to the level of greater trochanter of femur and divided into its terminal branches at this level. In our present study we report a case of higher division of left sciatic nerve inside the pelvis where common peroneal nerve passes above and the tibial nerve passes below the piriformis muscle.

The observations made in our present study are concordant with those made by earlier workers [1], [2], [4], and [6] who reported that sciatic nerve can divide at any level from its origin to its terminal division. Observations made by Saleem Itoo et al [7] also represents one of the levels at which sciatic nerve can divide into its terminal branches.

\section{Summaries and conclusion}

Sciatic nerve divides into its terminal branches at different levels. These variations are not so rare and knowledge of these variations is not only important for specialists and super specialists but also for paramedical staff. The variation reported by us is of great academic and clinical significance particularly for paramedics who are commonly involved in giving intramuscular injections in the gluteal region and are also responsible for iatrogenic traumatic palsy of the sciatic nerve. A sound knowledge of this anomaly is also important for neurophysiologists who perform nerve conduction tests. Orthopedicians and the General surgeons should also give due recognition and respect to this variation during surgical drainage of abscesses. The most common cause of serious sciatic nerve injury and consequent major medico legal claims is iatrogenic. It may be damaged in misplaced therapeutic injections into gluteus maximus. Sciatic nerve palsy occurs after total hip replacement surgery in about 1 percent of cases. 
Figure legends

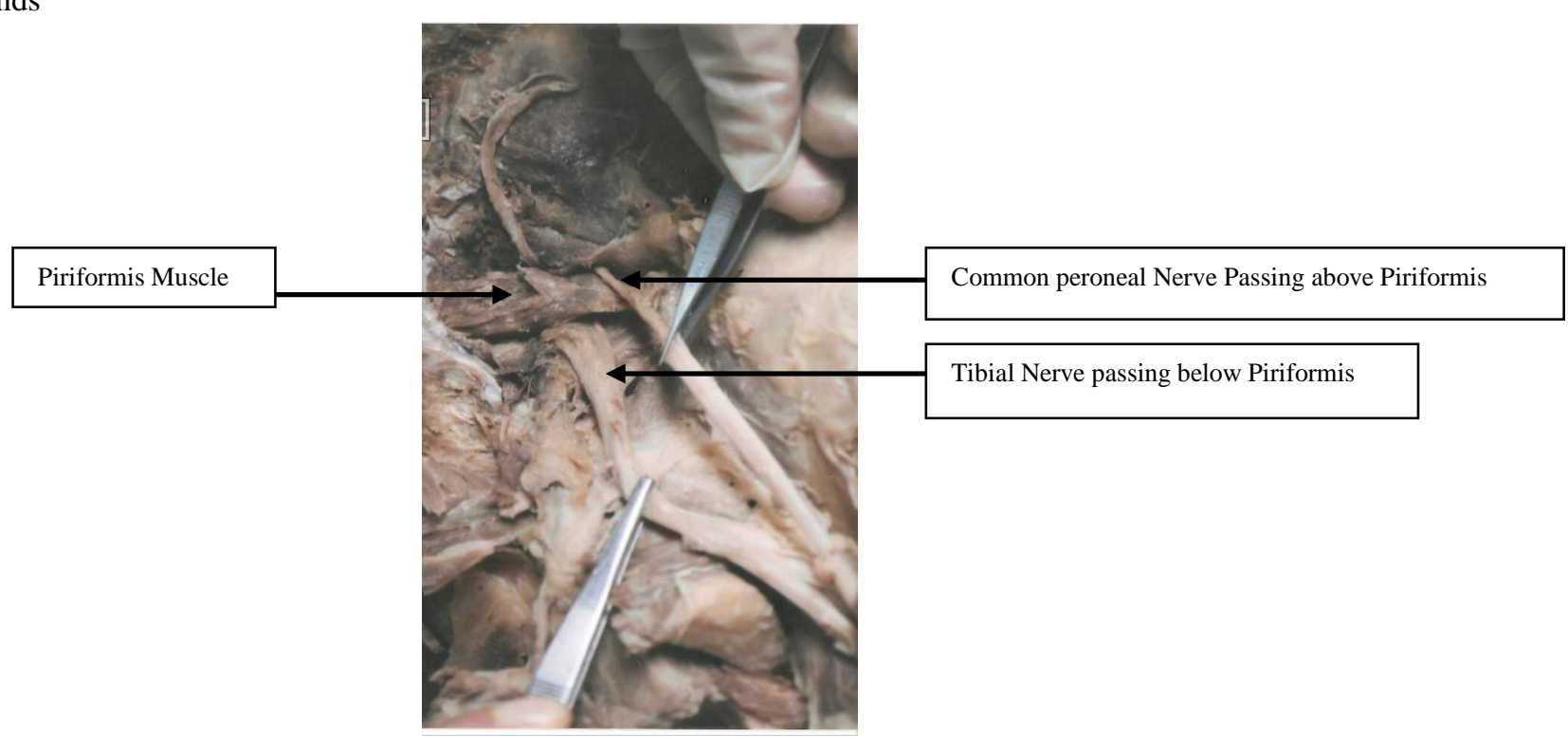

Fig. 1: Showing left Piriformis muscle sandwiched between Common peroneal and Tibial Components of Sciatic Nerve.

\section{References}

[1] Neeta V kulkarni,CLINICAL ANATOMY(A Problem solving approach), 2nd Edition.JAYPEE BROTHERS MEDICAL PUBLISHERS(P) LTD NEW DELHI,PANAMA CITY,LONDON Page :862.

[2] Keith.L.Moore,Clinically oriented Anatomy first edition reprinted in 1882,page 474-486.

[3] Cornelius Rosse and Penelope gaddam Rosse.Hollinshed,s Textbook of anatomy fifth edition, 1997,page 365-369.

[4] Standring S. Gray's Anatomy. 39th Ed. Elsevier Churchil Livingstone. 2005; 1456-58.

[5] Romanes GJ. Cunningham's Manual of Practical Anatomy. Volume 1, Upper and lower limbs. Oxford University Press. 1996; 167.

[6] R.Kangasuntheram,P sivanadassingham ,A Krishna Murti,Regional/functional and clinical Anatomy Ist. Edition page 384-388.

[7] Mohd. Saleem Itoo. Incidence of higher division of Sciatic Nerve in a sample of Indian population, KMJ, VOL: 5 No 3-4, July-September 2011, page 801-803. 